Karla de Araújo do Espírito Santo Pontes ${ }^{a}$ (iD) https://orcid.org/0000-0001-6560-5447

Simone Santos Oliveirab

(iD) https://orcid.org/0000-0002-1477-749X

Luciana Gomes ${ }^{b}$

(iD) https://orcid.org/0000-0003-2038-0859

Lúcia Rotenberg ${ }^{c}$

(iD) https://orcid.org/0000-0002-4132-2167

a Fundação Oswaldo Cruz (Fiocruz), Instituto Fernandes Figueira, Unidade Neonatal. Rio de Janeiro, RJ, Brasil.

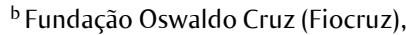
Escola Nacional de Saúde Pública Sergio Arouca, Centro de Estudos da Saúde do Trabalhador e Ecologia Humana. Rio de Janeiro, RJ, Brasil.

'Fundação Oswaldo Cruz (Fiocruz), Instituto Oswaldo Cruz, Laboratório de Educação em Ambiente e Saúde. Rio de Janeiro, RJ, Brasil.

Contato:

Lúcia Rotenberg

E-mail:

rotenber@ioc.fiocruz.br

As autoras declaram que o trabalho não foi subvencionado e que não há conflitos de interesses.

As autoras informam que o trabalho não foi apresentado em evento científico e que se baseia na tese de doutorado Dando nó em pingo dágua: os nós da enfermagem em uma unidade neonatal a partir do ponto de vista da atividade, de Karla de Araújo do Espírito Santo Pontes, defendida em 2014 na Escola Nacional de Saúde Pública Sergio Arouca, Fundação Oswaldo Cruz.

\section{O olhar da equipe de enfermagem sobre o trabalho em uma unidade neonatal: uma intervenção com foco na atividade}

\author{
The nursing team perspective on the work carried out at a \\ neonatal unit: an intervention focused on activity
}

\section{Resumo}

Objetivo: analisar as relações entre trabalho e saúde em equipe de enfermagem de uma unidade neonatal, numa perspectiva de compreender para transformar. Métodos: pesquisa-intervenção utilizando princípios da Ergologia e da Psicodinâmica do Trabalho para compreender e analisar a atividade de trabalho. Resultados: as adversidades relacionadas às condições de trabalho na unidade neonatal envolviam questões ambientais, relacionais e organizacionais incluindo a superlotação, o cuidado da criança com doenças crônicas, dificuldades no trabalho em equipe, ausência de reconhecimento profissional e ambiente de trabalho inadequado. Contudo, os trabalhadores de enfermagem conseguem estabelecer estratégias para lidar com as adversidades e desenvolver suas atividades de modo a produzir o cuidado com os pacientes. Discussão: a pesquisa-intervenção permitiu identificar os limites impostos pelas condições de trabalho e conhecer as estratégias utilizadas para a realização da atividade. A compreensão da história e do saber de cada trabalhador, no desenvolvimento da atividade, favorece tanto o reconhecimento do próprio trabalhador no investimento que faz para desenvolver a sua atividade de trabalho, quanto fortalece sua identidade pessoal, profissional e social, possibilitando, assim, a construção do sentido do trabalho.

Palavras-chave: unidade de terapia intensiva neonatal; enfermagem; saúde do trabalhador; ergologia; psicodinâmica do trabalho.

\begin{abstract}
Objective: to analyze the work and health relations in the nursing team of a neonatal unit aiming at understanding and improving these relationships. Methods: intervention research following principles of Ergology and Psychodynamics of Work to understand and analyze the work activity. Results: the adversities associated with working conditions in the neonatal unit involved environmental, relational and organizational matters, including overcrowding, healthcare of children with chronic diseases, difficulties to work as a team, lack of professional acknowledgement and inappropriate workplace. Nevertheless, the nursing professionals managed to adopt strategies to endure such adversities and go on caring for their patients. Discussion: the intervention research made it possible to identify the limits imposed by such working conditions, as well as the strategies adopted to overcome them. Understanding the history and knowledge of each worker, that makes the activity feasible, favors the recognition of the workers themselves in their efforts to be engaged, and strengthens their personal, professional and social identity, which enables constructing the meaning of work.
\end{abstract}

Keywords: neonatal intensive care unit; nursing; occupational health; ergology; psychodynamics of work. 


\section{Introdução}

A unidade neonatal (UN) tem como objetivo precípuo atender recém-nascidos (RN) em risco iminente de vida. Cada vez mais se incorporam tecnologias potentes, que têm conseguido salvar e prolongar a vida desses pacientes. O uso de tecnologias, a necessidade de diferentes categorias profissionais, a presença dos pais e o atendimento de $\mathrm{RN}$ cada vez mais prematuros estabelecem uma relação complexa entre máquinas, trabalhadores, usuários e suas famílias. Apesar dos avanços tecnológicos, o trabalhador de enfermagem é imprescindível para a efetivação cotidiana dos cuidados. O trabalho de cuidar muitas vezes não é perceptível porque não resulta em produto, e sim em serviço. O resultado do cuidado se dá no corpo de outra pessoa e as respostas dependerão de cada um em particular, além do tempo necessário para visualizar esses resultados.

Os trabalhadores de saúde das unidades neonatais vivenciam situações difíceis, uma vez que seu cotidiano envolve casos de emergência, risco de morte e tempo de internação prolongado, aumentando o vínculo entre o trabalhador, o paciente e sua família ${ }^{1}$. Aspectos da organização do trabalho em termos da divisão do trabalho, conteúdo das tarefas, sistema hierárquico e relações de poder, somados aos objetivos e metas da instituição podem levar a repercussões sobre a saúde dos trabalhadores. Gomes ${ }^{2}$ (p. 74) afirma que "se por um lado muito se tem avançado sobre tratamentos e cuidados oferecidos na Unidade de Terapia Intensiva Neonatal. Por outro ainda há muito o que se fazer no que diz respeito à saúde do trabalhador neste tipo de unidade". Acrescenta que boa parte das pesquisas em UN é sobre procedimentos, infecções hospitalares, causas de mortalidade ou sobre a relação das mães com o bebê e/ou a equipe, e que poucos estudos abordam o sofrimento e a saúde mental dos trabalhadores, o processo e as condições de trabalho.

Outros aspectos importantes são fatores de sofrimento no trabalho da enfermagem, como vínculo em mais de um emprego, dobras de plantões, horas extras e sobrecarga de trabalho sem descanso, que acabam resultando em fadiga, tensão e irritação ${ }^{3}$. Além disso, devido ao esforço físico diário, repetições de tarefas e realização do trabalho em pé, esses trabalhadores podem sofrer com o desgaste físico e mental.

Esse ritmo no cotidiano dessas unidades pode levar ao sentimento de frustração, raiva, falta de confiança em si próprio e diminuição da satisfação com o trabalho, podendo, inclusive, desencadear sintomas de depressão. Nogueira-Martins ${ }^{4}$ aponta que os trabalhadores de saúde precisam receber cuidados e que tratar dessa questão é fundamental para o desenvolvimento de ações e projetos em prol da humanização da assistência.

Diante desses desafios, o estudo aqui apresentado surgiu de algumas inquietações: o que permite esse trabalho continuar acontecendo apesar de tudo? Que percepção de prazer e sofrimento permeia o cotidiano desses trabalhadores? De que estratégias os trabalhadores de enfermagem lançam mão para construir um sentido ante as dificuldades no cotidiano desse ambiente potencialmente gerador de sofrimento? Que repercussões sobre a saúde desses trabalhadores podem advir de sua atividade?

Para lidar com essas questões, apoiamo-nos nas Clínicas do Trabalho, um conjunto de teorias que tem como foco de estudo a relação entre trabalho e subjetividade e que tem o propósito de subsidiar ações de transformações das situações de trabalho ${ }^{5}$. Em especial, tomamos como base a perspectiva ergológica, buscando trabalhar também com contribuições da Psicodinâmica do Trabalho (PDT).

O presente estudo é oriundo de uma ampla análise do trabalho de enfermagem em $\mathrm{UN}^{6}$ e teve por objetivo analisar as relações entre o trabalho e a saúde no cotidiano da equipe de enfermagem. Por meio de pesquisa intervenção, buscou-se compreender para contribuir com transformações nessas relações.

\section{Referencial teórico}

Utilizaram-se instrumentais teóricos e metodológicos que incorporam a experiência do trabalhador, por meio de sua participação como protagonista da análise e sujeito da transformação das situações de trabalho.

Em meio à complexidade que envolve a dinâmica da UN, optamos por analisar a atividade da equipe de enfermagem a partir da abordagem ergológica. Tendo Yves Schwartz como seu principal mentor, essa abordagem pretende conhecer mais as situações de trabalho e, sobretudo, intervir melhor sobre elas para transformá-las ${ }^{7}$.

Transformar efetivamente o trabalho passa pelo enriquecimento da representação dos atores de uma organização a respeito do trabalho real, bem como por acordos, compromissos e novas formas de projetar, gerenciar, comparar e avaliar, considerando a atividade de trabalho como fonte de informações e objetivo. Guérin et al. ${ }^{8}$ complementam que transformar significa contribuir para a concepção de situações de trabalho que promovam a saúde dos trabalhadores e nas quais estes possam exercer suas competências ao mesmo tempo num plano 
individual e coletivo, além de vivenciar possibilidades de valorização de suas capacidades.

O conceito de atividade sob o aspecto ergológico "é uma concepção que atravessa diversas áreas de conhecimento. É um conceito de circulação multidisciplinar que pretende instrumentalizar e redescobrir fronteiras, objetos e metodologias diversas, sobretudo no mundo do trabalho" (p. 5) ${ }^{9}$. A atividade de trabalho, para Schwartz ${ }^{10}$, compreende aquilo que deve ser ajustado, rearranjado, inventado pelos trabalhadores, sendo o elemento central organizador e estruturante da situação de trabalho. Esse reajustamento é sempre tentativa de reinventar maneiras de fazer e de viver as contradições presentes. Os trabalhadores investem, fazem escolhas e arbitram entre diferentes normas, às vezes contraditórias.

Lhuilier ${ }^{11}$ considera que pouco se sabe a respeito dos efeitos do trabalho sobre a saúde. Essas relações são multifatoriais e não podem ser vistas sob um único aspecto. Contudo, muitas vezes são reduzidas, eufemizadas ou mascaradas. Além disso, "a negação das origens, dos processos de sofrimento e dos riscos do trabalho se desdobram em uma invisibilidade crescente do trabalho real e contribui para agravar o sofrimento psíquico" (p. 14) ${ }^{11}$. A perspectiva de análise das relações entre saúde e trabalho a partir da atividade implica considerar a complexidade dos dados presentes na execução do trabalho, avançando para além das concepções prescritas ou os estudos que se atêm apenas às prescrições ${ }^{11}$.

Buscando ampliar o conhecimento dos aspectos invisíveis do trabalhar, acrescentamos a contribuição da PDT, disciplina produtora de conhecimentos e práxis, desenvolvida na França por Christophe Dejours. A PDT aborda a dinâmica prazer-sofrimento no trabalho, o homem e a organização do trabalho, mas também as situações concretas de trabalho e os detalhes da sua dinâmica interna $^{12}$. É voltada para o conteúdo simbólico do trabalho, com seus aspectos invisíveis, e para as relações subjetivas do trabalhador com sua atividade, explorando pontos como a construção da identidade, inteligência da prática, mobilização subjetiva, dinâmica do reconhecimento, criatividade e cooperação no trabalho.

Tanto a Ergologia quanto a PDT contaram em sua base inicial com a Ergonomia da Atividade, que busca analisar o trabalho no momento do seu desempenho para transformá-lo no contexto de suas situações $^{8}$. Essa disciplina deu sua grande contribuição ao demonstrar que existe um hiato entre a tarefa prescrita e a atividade real do trabalho. E essa distância pode ser verificada mesmo nas atividades mais simples, consideradas como de mera execução ${ }^{12}$. A Ergonomia da Atividade busca compreender a atividade situada dentro de um contexto técnico, social e histórico.

Para Schwartz (p. 31) 13, a atividade humana "está sempre em um dado meio, em negociação de normas. Trata-se de normas anteriores à própria atividade: a atividade negocia essas normas em função daquilo que são as suas próprias”. Para a Ergologia, qualquer que seja a situação, esta sempre envolverá uma negociação e cada pessoa no trabalho tentará, ainda que possa não ser bem-sucedida, recompor esse meio de forma singular para que sinta que está como gostaria que fosse o universo que a circunda. O trabalho é, portanto, um espaço constituinte da individualidade desse trabalhador, gerando ganhos fundamentais para sua formação.

\section{Métodos}

O campo de pesquisa foi a Unidade Neonatal do Instituto Nacional de Saúde da Mulher, da Criança e do Adolescente Fernandes Figueira, localizada no município do Rio de Janeiro, considerada um órgão auxiliar do Ministério da Saúde na tarefa de desenvolver, coordenar e avaliar as ações integradas, direcionadas à área da saúde feminina e infanto-juvenil em âmbito nacional.

A pesquisa-intervenção teve como sujeitos a equipe de enfermagem (enfermeiras e técnicos de enfermagem), que é distribuída em seis plantões de 12 horas, sendo três noturnos e três diurnos, além dos diaristas. Dentre os 53 trabalhadores participantes deste estudo, 71,7 \% eram técnicos de enfermagem e $28,3 \%$ eram enfermeiras.

Com o foco na atividade, utilizamos as ferramentas metodológicas que buscaram convocar os trabalhadores para refletirem sobre suas práticas, na perspectiva de ampliar seus recursos para ação.

O primeiro movimento da pesquisa-intervenção foi a apresentação da proposta para cada equipe de plantão por meio de um cartaz exposto na sala de convívio. O segundo foi a realização das fotografias, com inspiração nas oficinas de fotos, dispositivo proposto por Osório-da-Silva et al. ${ }^{14}$, para coanálise do trabalho. Por meio do método de autoconfrontação cruzada, desenvolvido por Clot e Faita ${ }^{15}$ no âmbito da Clínica da Atividade, essa ferramenta utiliza o registro fotográfico para compartilhar com os trabalhadores a análise de suas atividades, possibilitando a ampliação de sua capacidade de ação. Sendo assim, foi disponibilizada em cada plantão durante 12 horas, uma câmera fotográfica digital. Solicitou-se que fotografassem situações que 
considerassem positivas ou negativas para a produção da saúde no ambiente de trabalho.

O terceiro movimento foi a análise das fotos com o grupo constituído pelas pesquisadoras e participantes. Os comentários foram gravados, sendo posteriormente selecionados os representativos dos pontos mais discutidos em cada situação fotografada.

O quarto movimento correspondeu aos encontros sobre o trabalho, ferramenta proposta pela Ergologia que possibilita um diálogo-debate sobre a atividade, reunindo os saberes disciplinares e os protagonistas da atividade, interessados no encontro/confronto entre conhecimento e experiência, visando abordar as situações de trabalho em sua singularidade. Denominado de Dispositivo Dinâmico de Três Polos $(\mathrm{DD} 3 \mathrm{P})^{16}$ tal dispositivo tem a perspectiva de transformar positivamente o trabalho. O primeiro polo é o dos saberes formais sobre o trabalho, composto por diversas disciplinas e campos de conhecimento; o segundo é dos saberes advindos da experiência prática dos trabalhadores; o terceiro é pensado como o que propicia o encontro fecundo dos dois primeiros. Este polo é conhecido como polo das exigências éticas e epistemológicas, pois trata da ética relacionada à construção das relações de parceria, que se baseia na ideia de ver o outro como seu semelhante.

Para a análise das fotografias, os seguintes tópicos alicerçaram as discussões: situações escolhidas para serem fotografadas, sentido que a situação fotografada evocava e comentários dos participantes sobre a fotografia. As discussões foram registradas por meio de gravação em áudio e transcritas logo em seguida à sua ocorrência, possibilitando a pré-análise do material pelas pesquisadoras para dar sequência à produção do material.

Após a leitura das transcrições referentes aos sete grupos, selecionamos 16 comentários, que sintetizavam os principais pontos discutidos. Esses materiais, cuja categorização é apresentada nos Resultados, serviram para orientar os conteúdos abordados nos encontros sobre o trabalho.

Foram realizados sete encontros sobre o trabalho, sendo um para cada equipe do plantão e um para os diaristas, totalizando 42 participantes. Os participantes deveriam escolher, entre 16 comentários selecionados da terceira etapa, cerca de cinco para serem debatidos. Nesse processo de definição, os trabalhadores colocaram a sua atividade em debate. Ao final das discussões foi solicitado a cada grupo que elaborasse um painel que expressasse o sentido do trabalho na UN que foi exposto na Instituição, como parte da intervenção (Figura 1).

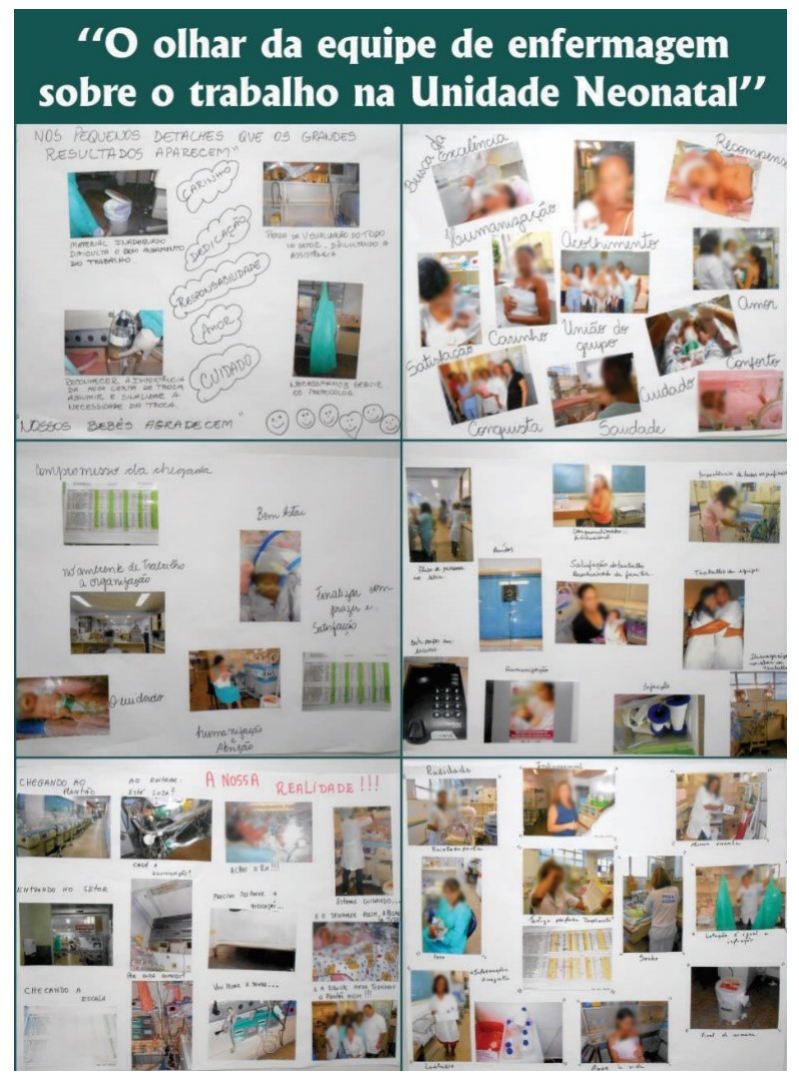

Figura 1 Painéis finais

Em consonância com a abordagem teórico-metodológica adotada, que implica a coanálise do trabalho a partir das oficinas de fotos, assim como a perspectiva de transformação do trabalho promovida pelo DD3P, reconhecemos a dimensão de intervenção da pesquisa.

A pesquisa foi aprovada pelo Comitê de Ética do Instituto Fernandes Figueira (número 02224212.900005240), tendo sido autorizada a identificação da instituição nos produtos da pesquisa. Em todas as etapas, foi respeitada a não identificação dos sujeitos, que são referidos, no presente texto, por seus pseudônimos. Nos resultados e discussão também utilizamos nomes fictícios para ilustrar os comentários.

\section{Resultados e discussão}

Para os encontros sobre o trabalho, elaboramos uma categorização dos comentários selecionados a partir da oficina de fotos, cientes de que outras dimensões poderiam ser abordadas: prazer/relação com o usuário e a família, demanda do processo de trabalho/valor da vida, reconhecimento profissional, 
trabalho em equipe/processo de trabalho, trabalho em equipe/valor do trabalhador, comprometimento/ valor social, trabalho prescrito e trabalho real e estratégia de defesa.

O olhar voltado para a atividade nos permitiu constatar que para realizar seu trabalho os trabalhadores da enfermagem dão verdadeiros "nós em pingo d'água", ou seja, diante das adversidades relacionadas às condições de trabalho, que envolvem questões de toda ordem ambientais, relacionais, organizacionais -, ainda assim conseguem desenvolver suas atividades e produzir o cuidado. Segundo Vianna ${ }^{17}$, os trabalhadores dão "nó em pingo d'água" quando, embora as circunstâncias pareçam desfavoráveis, eles dão um "jeitinho" para fazer o que deve ser feito, desenvolvendo habilidades para lidar com inúmeros desafios.

Um dos "nós" considerados pelos participantes foi a superlotação, que envolve acomodação dos leitos, sobrecarga de trabalho e quantitativo de pessoal. Vera revela, na fala a seguir, que não existe a possibilidade de não dar conta do que se pede, principalmente por estar lidando com vidas:

A única coisa que eu acho ruim é o seguinte: independente de a gente ter vaga ou não, a gente sempre tem vaga. Precisou ir para UTI, a gente sempre tem vaga. Então isso que é ruim para a gente porque ocupa nosso espaço, mas a gente sempre tem que arranjar um cantinho para enfiar a criança. (Vera)

Os trabalhadores citam que por ser uma unidade de referência para gestação de alto risco fetal, muitas vezes a parturiente chega em trabalho de parto e não há tempo hábil para conduzi-la a outra instituição. Em algumas situações, elas trazem um mandato judicial determinando a internação, de forma que é necessário reorganizar os leitos para acomodar mais um RN, como menciona Lívia:

O espaço é pequeno, tá? O quantitativo de crianças que vai aumentando e a gente bate na tecla que não tem vaga, que não tem espaço físico, não tem vaga e eles não querem saber, não tem respeito nenhum pelo profissional e a gente sempre vai dando um "jeitinho". Empurra daqui, empurra dali, cinco incubadoras num box, entendeu? Isso já gera um estresse. Às vezes a gente está recebendo plantão, não tem onde botar, mas vai nascer. É assim: vai nascer, se vira, dá seu jeito, entendeu? Isso quando avisa. Às vezes chegam com a criança no braço e diz: toma, é seu. (Lívia)

Marlene acrescenta a falta de pessoal, em especial em relação ao trabalhador que faz a reposição de material, o que remete à importância do trabalho desempenhado por cada membro da equipe. Para ela, essa ausência não só compromete sua atividade, mas também a atividade dos demais envolvidos, demandando um "jeitinho".
[...] é necessário cuidar da criança e ao mesmo tempo repor o material, que é uma coisa complicadíssima. (Marlene)

Ao fazer o seu trabalho e de outro trabalhador, a situação exemplifica a forma enigmática do uso de si no trabalho, indo além do que lhe é prescrito.

A questão referente ao trabalho em equipe é um outro "nó" que requer um engajamento do sujeito para a superação de desafios decorrentes da ausência de um trabalhador. No entanto, ao envolver vários sujeitos no processo de trabalho, as chances de conflito serão maiores, visto que cada um traz os seus valores para o debate. Alguns desses conflitos podem ser gerados a partir do que Lívia avalia como falta de compromisso para com o trabalho em equipe, como ela exemplifica:

Eu venho trabalhar e eu quero dar o meu melhor, mas tem gente que não quer. Aí já começa o estresse, porque você vem faz o seu certo e o seu colega não tá nem aí, empurra com a barriga. Aí você faz o quê? Caraca, é difícil! (Lívia)

Num ambiente em que as tarefas se entrelaçam de modo tão peculiar, as dificuldades de relacionamento são bastante prejudiciais, podendo interferir na dinâmica do trabalho e na satisfação do trabalhador. Como a perspectiva ergológica ${ }^{18}$ sinaliza, as equipes não funcionam da mesma maneira, pois estão condicionadas à atividade de cada um.

Júlia relatou uma situação a qual não conseguiu trazer por meio da fotografia:

\footnotetext{
Às vezes a gente saindo de plantão, quando você vai passar o plantão e o cara não entende o quanto a noite foi complicada e que às vezes você deixou um furo ou outro. E aí o que você vê na passagem do plantão é uma falta de compreensão do colega, de algum furo que você tenha deixado passar. Eu nem considero furo, porque o trabalho de enfermagem é questão de continuidade. Eu não consegui chegar até ali, mas o outro vai prosseguir. (Júlia)
}

O "furo" refere-se a algum procedimento que deveria ter sido feito, mas não foi. Por exemplo: esquecer de verificar uma pressão arterial porque teve dificuldades de lidar com um número grande de tarefas para o quantitativo de pessoal, inadequado ao número de RN. Os profissionais sabem que situações como essa exigem escolhas dramáticas do uso de si, que são vivenciadas sobre o que deve e o que pode ser feito e as possíveis consequências. O incômodo maior não vem da percepção de que somos falíveis e temos limitações e sim da negação entre os pares, do não reconhecimento de tudo o que foi possível fazer, da falta de empatia e solidariedade. 
A relevância atribuída às questões da equipe também foi observada por Souza ${ }^{19}$, ao analisar as relações entre a forma com que enfermeiras e técnicas de enfermagem de uma UTI neonatal desenvolvem o cuidado e a saúde das trabalhadoras. As relações em equipe se mostraram um elemento estruturante para a saúde das trabalhadoras.

A superlotação e a falta de pessoal provocam um entrave na relação trabalho-saúde, de forma semelhante à apontada por Souza ${ }^{19}$. A demanda das atividades em um tempo definido gera um ritmo intenso de trabalho, levando os trabalhadores a comprometerem suas refeições e idas ao banheiro, prejudicando o cuidado de si, como mostram alguns exemplos:

O estresse acaba fazendo com que, quem já tem problema de pressão, a pressão aumenta. Você está de plantão à noite, o plantão está tumultuado e quando você lembra já passou o horário do remédio. Você só vai lembrar quando a cabeça está latejando aí você lembra: ih esqueci o remédio. (Carolina)

A Lívia que era vítima de infecções urinárias por conta de: "Segura a urina, não dá tempo de ir ao banheiro não”. (Bianca)

A esse respeito, nossas observações corroboram as de Gomes ${ }^{2}$ em relação à sobrecarga de trabalho na UN de outro hospital, o que impede que as trabalhadoras sequer consigam se sentar durante os plantões.

Outro "nó" que necessita do "jeitinho" peculiar da equipe neonatal é o cuidado com a criança pediátrica. A sobrevivência de RN prematuros, com malformações congênitas ou com necessidade de intervenção cirúrgica, decorrente da evolução tecnológica, modificou o perfil dos pacientes, aumentando o tempo de internação. Consequentemente, a complexidade do cuidado terapêutico, curativo e preventivo também mudou, sobressaindo as peculiaridades na assistência ao RN e à criança pediátrica, o que exige competência técnica e competência na ação ${ }^{20}$.

Segundo os trabalhadores, em várias situações a criança permanece até oito meses de vida na unidade devido à falta de vagas na enfermaria pediátrica. Esse é mais um exemplo da distância entre o trabalho prescrito e o real, ou seja, a prescrição visa o cuidado neonatal e o real abrange o cuidado pediátrico. Essa distância ganha destaque, mais uma vez, no relato a seguir:

A filha de Camila, eu dei dieta, aspirei, dei dieta Daqui a pouco ela começa a gritar. Dei um pouquinho de colo, ela foi indo e dormiu e eu coloquei ela lá no berço. Não deu 10 minutos ela começa com o desespero. Eu apaguei todas as luzes do setor para ver se ela melhorava. Não, ela piorou. Eu falei: meu Deus não é possível. Então coloquei ela no colo. Ela agarrou a minha roupa e ela dormiu assim. (Carolina)
Ao lançar mão de várias estratégias, buscando dar conta do choro do bebê, Carolina inventa um jeito de lidar com aquela dificuldade, ilustrando a complexidade do objeto de trabalho hospitalar, já que ele (o objeto) é "[...] também humano. Interage com o trabalhador" (p. 161) ${ }^{21}$. Ao mesmo tempo, a fala revela o papel do carinho nessa situação (como discutido adiante), o que não consta em nenhuma prescrição. Trata-se, na visão da Ergologia, de uma ação da trabalhadora a partir de sua mobilização em acalmar o bebê, que contribui para dar sentido a seu trabalho.

Os trabalhadores se deparam com variabilidades no processo de trabalho, referentes às demandas individuais dos RN que vão de encontro com as normas e rotinas institucionais. Eles se encontram, nesse momento, diante de um dilema: de um lado, a organização espera que eles cumpram o previsto e, de outro, se seguirem a prescrição não darão conta da nova situação.

Do ponto de vista da Ergologia, a saída é não seguir as regras para desenvolver o trabalho-agir sobre a sua situação de trabalho de maneira ativa, mesmo que de modo ínfimo. Para Schwartz ${ }^{7}$, trabalhar é fazer uma releitura do prescrito, renormatizar. Assim, os trabalhadores não serão simplesmente sujeitos que devem se adaptar à organização e às condições do trabalho, mas sim sujeitos que devem recriar a tarefa, o que implica a possibilidade da transformação do trabalho.

Carolina acrescenta:

Essa UTI admite só bebês crônicos, pois aceita bebês com patologias que muitas unidades não aceitam. [...] A gente fica sem condições de dar vagas para outras crianças, porque essas não são aceitas em outros lugares. Então tem a questão do apego, do desgaste emocional muito grande, a gente se envolve demais [...]. As pessoas questionam como a gente consegue trabalhar assim. (Carolina)

As renormatizações citadas pelas trabalhadoras revelaram uma parte invisível do trabalho: dar carinho, ato que também é declarado por Giovana:

A gente se torna mãe das crianças crônicas. [...] É muito delicado para a gente, porque a gente tem pacientes graves e crianças que não são graves e que estão morando dentro da UTI. (Giovana)

Por mais que as diferentes situações de tensionamento das relações trabalho-saúde possam assumir um rumo patogênico, elas também podem produzir saúde e prazer. Lucinha traduz um desses bons resultados consequentes do fazer:

Aqui é o lado superbom da gente trabalhar. A gente vê a mãe com o neném no colo supercontente, um dia antes de ir embora. (Lucinha) 
Ao identificar o lado positivo do seu trabalho, Lucinha evidencia quanto essa satisfação favorece o sentido do trabalho. A respeito do prazer associado à alta, Souza ${ }^{19}$ observa como esse momento traduz, para a equipe de uma UTI Neonatal, o trabalho bem-sucedido no sentido da produção de cuidados em saúde. Assim, a alta é vista por aqueles autores como a concretização do resultado do esforço da equipe.

Assim, o trabalho é marcado por essa ambivalência, de um lado situações que são fontes de prazer, em que se sentem valorizados e reconhecidos e, de outro, situações em que seu trabalho não é reconhecido, sendo mesmo invisibilizado. Nesse sentido, o reconhecimento profissional também pode ser visto como um nó, a depender da forma como o trabalho é organizado, que pode gerar diversos tipos de desgaste, perda de expectativa de realizá-lo com qualidade e desmotivação para desenvolvê-lo. A organização do trabalho pode levar também à destruição de mecanismos de cooperação na equipe, queda da produção, absenteísmo e níveis elevados de sofrimento psíquico. No entanto, quando os esforços, as angústias, as dúvidas, as decepções e os desalentos adquirem sentido, fica clara a afirmação de Dejours ${ }^{12}$ de que a identidade constitui a armadura da saúde mental. Dessa forma, o reconhecimento pode transformar o sentido do trabalho.

Outro ponto altamente mobilizador nas discussões refere-se à distância entre o prescrito pela Política Nacional de Humanização (PNH) ${ }^{22}$ e o real. Suas diretrizes deveriam estar presentes em todas as ações da saúde para favorecer a troca e a construção de saberes, o diálogo entre trabalhadores, o trabalho em equipe e a consideração às necessidades, desejos e interesses dos diferentes atores do campo da Saúde ${ }^{24}$. Porém destacaram que, na prática, a valorização dos trabalhadores está aquém do que está prescrito por essa política, conforme observamos na fala de Ricardo:

\begin{abstract}
A gente tem a questão da humanização que eu acho importantíssima, os nossos pacientes merecem isso. Mas assim, eu vejo muito essa discussão da humanização em cima do paciente, e a nossa humanização? Quando é que eu sou humanizado? Porque eu sou largado aqui dentro. Eu me sinto largado. (Ricardo)
\end{abstract}

A instituição exige que os trabalhadores cumpram em suas ações o que está preconizado na $\mathrm{PNH}$. Por outro lado, ela não contempla as necessidades dos trabalhadores em relação a condições adequadas de trabalho para a efetivação de suas atividades dentro desse padrão de humanização. Esse sentimento de desamparo decorre dos enfrentamentos que precisam fazer na atividade sem o apoio e o respaldo da instituição.

Somos cobrados para humanizar, mas não funciona exatamente como deveria. Eu entendo assim, para você cobrar, você tem que motivar seus funcionários oferecendo um meio para que ele possa trabalhar de uma forma adequada. E uma das coisas que a gente mais reclamou na época das fotos é a gente não ter uma sala adequada para refeição. A gente tem que comer e aquele lugar é desumano. (Ângela).

A questão da humanização também abarca a área física atual, que está obsoleta para atender o crescimento da demanda de assistência institucional, afetando, portanto, o cuidado ao paciente e ao trabalhador. De fato, a questão do espaço apareceu nas discussões dos encontros como "pólvora", tendo em vista a ambiência degradada.

A sala de convívio onde a gente almoça. A gente come ali curvado. Que eu acho maravilhoso você ter 7, 8 cabeças naquele lugar. Desculpa, parece um curral. O que acontece? O que eu vejo com isso? No dia que você [pesquisadora] apresentou essa pesquisa, eu lembro que você fez um comentário que era do funcionário chegando, que ele chegava com um pique e durante o processo ele ia perdendo esse pique. E eu acho que tem muito a ver com isso, sabe? Você chega e depois como eu sou tratado? Eu não me sinto valorizado nisso aqui, me desculpa. Parece que eu venho e tenho que cumprir a minha função e vou embora. Você não importa, você é o de menos, como você vai ficar aqui é o de menos. Me parece isso, sinceramente. (Ricardo)

A fala anterior remete à observação de Souza ${ }^{19}$ sobre o questionamento da equipe de uma UTI neonatal (fonoaudiólogos, médicos, técnicos de enfermagem, entre outros profissionais) em relação à "humanização" de seu ambiente de trabalho.

Em se tratando de valorização dos trabalhadores, entendemos que existem duas ações centrais: democratizar as relações de trabalho por meio da inclusão dos trabalhadores no processo de gestão e transformar as condições concretas de trabalho, como sub-remuneração, relações contratuais precarizadas e injustas no trabalho e ambiência degradada, que consistem nos fatores que interferem na produção de saúde dos que cuidam ${ }^{23}$.

\section{Considerações finais}

Por mais que esse cenário seja desanimador, o que se constatou foi a luta diária dos trabalhadores pela conquista da saúde.

Analisar o trabalho da enfermagem foi uma experiência rica, considerando o patrimônio que o grupo detém e o quanto tem a ensinar sobre as situações de trabalho. As ferramentas teóricas e metodológicas utilizadas beneficiaram sobremaneira esta pesquisa-intervenção, visto que possibilitaram descortinar a atividade sob um ângulo diferente de ver o trabalho 
apenas como a execução de procedimentos. Vimos o trabalho como construção de uma história, um momento de vida que jamais se reproduz de forma idêntica, o que é um diferencial significativo para atingir o objetivo proposto. Promover ações nas quais os trabalhadores colocaram seu cotidiano de trabalho em foco contribuiu para desnaturalizar os processos de trabalho, ampliando o olhar dos trabalhadores para os aspectos presentes na atividade e tornando o trabalho mais visível. Pode-se dizer que esta pesquisa-intervenção contribuiu para fortalecer o poder de agir individual e coletivo do grupo, proporcionando novas possibilidades de ação. A análise do trabalho a partir do debate promovido nos encontros permitiu identificar as dificuldades e os limites impostos pelas condições de trabalho, além de conhecer os saberes e as estratégias utilizadas para a realização da atividade.

Em consonância com a perspectiva adotada, podemos afirmar que os resultados fortalecem a concepção de que a história e o saber de cada trabalhador são essenciais para o desenvolvimento da atividade. Essa visão do trabalho tanto favorece o reconhecimento do investimento que o trabalhador faz de si, como fortalece sua identidade pessoal, profissional e social, possibilitando, assim, a construção do sentido do trabalho. Esperamos que este estudo possa oferecer subsídios necessários para que as organizações de trabalho estabeleçam intervenções visando a valorização do trabalho e saúde dos trabalhadores.

\section{Contribuições de autoria}

Todas as autoras participaram da autoria intelectual da pesquisa-intervenção, assim como da interpretação dos resultados, da redação do artigo e da aprovação da sua versão final publicada, e assumem integral responsabilidade pelo trabalho e o conteúdo aqui publicado.

\section{Referências}

1. Carvalho M. Prefácio. In: Moreira MEL, Braga NA, Morsch DS, organizadores. Quando a vida começa diferente: o bebê e sua família na UTI Neonatal. Rio de Janeiro: Editora Fiocruz; 2006. p. 9-11.

2. Gomes L. Trabalhar em UTI neonatal: os desafios da relação de serviço e a saúde das/os técnicas/os de enfermagem [tese na Internet]. Rio de Janeiro: Fundação Oswaldo Cruz; 2011 [citado em 2 set 2020]. Disponível em: https://www.arca.fiocruz.br/ handle/icict/16928

3. Oliveira BRG, Lopes TA, Viera CS, Collet N.O processo de trabalho da equipe de enfermagem na UTI Neonatal e o cuidar humanizado. Texto Contexto Enferm [Internet]. 2006 [citado em 2 set 2020];15(Spec):105-13. Disponível em: https:// www.scielo.br/scielo.php?script=sci_arttext\&pid $=$ S0104-07072006000500012

4. Nogueira-Martins MCF. Humanização da assistência e formação do profissional de saúde. Psychiatry On Line Brasil [Internet]. 2003 [citado em 25 out 2013]8(5). Disponível em: http://www. polbr.med.br/ano03/artigo0503_1.php

5. Bendassolli PF, Soboll LA. Clínicas do trabalho: novas perspectivas para compreensão do trabalho na atualidade. São Paulo: Atlas; 2011.

6. Pontes KAES. Dando nó em pingo d'água: os nós da enfermagem em uma unidade neonatal a partir do ponto de vista da atividade [tese na Internet]. Rio de Janeiro: Fundação Oswaldo Cruz; 2014 [citado em 2 set 2020]. Disponível em: https://www.arca. fiocruz.br/handle/icict/13073
7. Schwartz Y. Trabalho e ergologia. In: Schwartz Y, Durrive L, organizadores. Trabalho e ergologia: conversas sobre a atividade humana. Niterói: Eduff, 2010. p. 25-46.

8. Guérin F, Laville A, Daniellou F, Duraffourg J, Kerguellen A. Compreender o trabalho para transformá-lo: a prática da ergonomia. São Paulo: Blucher; 2001.

9. Souza KMO, Velloso MP, Oliveira SS. A profissão de bombeiro militar e a análise da atividade para compreensão da relação trabalho-saúde: revisão da literatura. In: VIII Seminário de Saúde do Trabalhador (em continuidade ao VII Seminário de Saúde do Trabalhador de Franca) e VI Seminário "O Trabalho em Debate" [Internet]; . UNESP/ USP/STICF/CNTI/UFSC, 25 a 27 de setembro de 2012; - UNESP- Franca, /SP. Franca: Unesp; 2012 [citado em 2 set 2020]. Disponível em: http://www. proceedings.scielo.br/pdf/sst/n8/21.pdf

10. Schwartz Y. Manifesto ergológico. In: Bendassoli P, Soboll LAP, editores. Clínicas do trabalho: novas perspectivas para a compreensão do trabalho na atualidade. São Paulo: Atlas; 2010. p. 132-166.

11. Lhuilier D. A invisibilidade do trabalho real e a opacidade das relações saúde-trabalho. Trabalho \& Educação. 2012 [citado em 2 set 2020];21(1):13-38. Disponível em: https://periodicos.ufmg.br/index. php/trabedu/article/view/8832

12. Dejours C. Addendum: da psicopatologia à psicodinâmica do trabalho. In: Lancmann S, Sznelwar LI, organizadores. Christophe Dejours: da 
psicopatologia à psicodinâmica do trabalho. 2a ed. Rio de Janeiro: Editora Fiocruz; 2008. p. 49-106.

13. Schwartz Y. Trabalho e ergologia. In: Schwartz Y; Durrive L, organizadores. Trabalho e ergologia: conversas sobre a atividade humana. Niterói: Eduff; 2010. p. 25-36.

14. Osório-da-Silva C, Pacheco AB, Barros MEB. Oficinas de fotos: experiências brasileiras em clínica da atividade. Cad Psicol Soc Trab [Internet]. 2013 [citado em 2 set 2020];16(Spec1):12131. Disponível em: http://pepsic.bvsalud. org/scielo.php?script $=$ sci_arttext\&pid $=\mathrm{S} 1516-37172013000300012$

15. Clot Y, Faita D. Genres et styles en analyse du travail: concepts et méthodes, Travailler [Internet]. 2000 [citado em 2 set 2020];4:7-42. Disponível em: http://psychanalyse.cnam.fr/revue-travailler/ presentation-et-sommaire/numero-4/theoriegenres-et-styles-en-analyse-du-travail-concepts-etm-thodes--467242.kjsp

16. Durrive L. Pistas para o ergoformador animar os encontros sobre o trabalho. In: Schwartz Y, Durrive L, organizadores. Trabalho e ergologia: conversas sobre a atividade humana. Niterói: Eduff; 2010. p. 309-18.

17. Vianna EC. Entre poucas prescrições e subversões: o jeitinho de fazer saúde dos agentes comunitários de Manguinhos [tese na Internet]. Rio de Janeiro: Fundação Oswaldo Cruz; 2013. Disponível em: https://www.arca.fiocruz.br/handle/icict/40234

18. Schwartz Y. A dimensão coletiva do trabalho: as entidades coletivas relativamente permanentes.
In: Schwartz Y, Durrive L, organizadores. Trabalho e ergologia: conversas sobre a atividade humana. Niterói: Eduff; 2010. p. 149-64.

19. Souza AMRZ. Atividade de cuidados em UTI Neonatal: uma análise das relações entre trabalho de enfermagem e saúde [dissertação na Internet]. Rio de Janeiro: Fundação Oswaldo Cruz; 2010 [citado em 2 set 2020]. Disponível em: https:// www.arca.fiocruz.br/handle/icict/2310

20. Schwartz Y. Trabalho e uso de si. Pro-Posições [Internet]. 2016 [citado em 2 set 2020];11(2):34-50. Disponível em: https://periodicos.sbu.unicamp.br/ ojs/index.php/proposic/article/view/8644041

21. Machado JM, Correa MV. Reflexões sobre a observação do processo de trabalho: introduzir o conceito de vida no trabalho na análise das relações entre processo de trabalho em saúde. In: Seminário Nacional Saúde Ambiente e Processo de Desenvolvimento; 2000; Rio de Janeiro, RJ. Rio de Janeiro: Fundação Osvaldo Cruz; 2000.

22. Brasil. Ministério da Saúde. Humaniza SUS: documento base para gestores e trabalhadores do SUS [Internet]. Brasília, DF; 2010 [citado em 2 set 2020]. Disponível em: https://bvsms.saude.gov. br/bvs/publicacoes/humanizasus_documento_ gestores_trabalhadores_sus.pdf

23. Brasil. Ministério da Saúde. Formação e intervenção [Internet]. Brasília, DF; 2010 [citado em 2 set 2020]. Disponível em: http:// bvs.saude.gov.br/bvs/publicacoes/cadernos_ humanizaSUS.pdf 